\title{
Comportamento informacional versus comunicação: aplicação de modelos em contextos multidisciplinares
}

\author{
Cecília Morena Maria da Silva \\ Jonathan Rosa Moreira \\ Juliana Rocha de Faria Silva
}

Universidade de Brasília - UnB, Brasil

\section{REVIEW}

\begin{abstract}
Resumo
Este artigo trata do comportamento informacional como subsídio para o desenho de modelos de comunicação nas áreas de Ciência da Informação, Biblioteconomia e Música. A proposição de modelos de comunicação está fundamentada nos modelos de Tubbs e Moss (2003), Garvey e Griffith (1972), adaptado por Hurd (1996), e Wilson (1999). Para tanto, levantaram-se as questões: (i) quais são as competências informacionais requeridas dos bibliotecários que atuam como mediadores nos processos de comunicação científica e comportamento informacional do usuário, no contexto educacional?; (ii) quais as necessidades dos pesquisadores da área de música e como produzem, buscam, utilizam e acessam o conhecimento científico de sua área?; e (iii) como os contextos envolvidos nos processos de colaboração científica influenciam na produção científica da área de Ciência da Informação no Brasil? O artigo faz uma revisão de literatura a respeito do comportamento informacional e de sua inserção na comunicação científica considerando a influência do contexto e/ou situação dos objetos envolvidos nas questões motivadoras. A hipótese é que o comportamento informacional do usuário em diferentes contextos e situações influenciam na definição de um modelo de comunicação científica. Ao final, conclui-se que um mesmo conceito, ou um conjunto de conceitos pode ser utilizado sob diferentes perspectivas, alcançando-se, deste modo, diferentes resultados.
\end{abstract}

Palavras-chave

Biblioteconomia ; Ciência da informação ; Comportamento informacional ; Comunicação científica ; Comunicação organizacional ; Informação musical ; Mediação da informação

\section{Information behavior versus communication: application models in multidisciplinary settings}

\begin{abstract}
This paper deals with the information behavior as support for models of communication design in the areas of Information Science, Library and Music. The communication models proposition is based on models of Tubbs and Moss (2003), Garvey and Griffith (1972), adapted by Hurd (1996) and Wilson (1999). Therefore, the questions arose: (i) what are the informational skills required of librarians who act as mediators in scholarly communication process and informational user behavior in the educational environment?; (ii) what are the needs of music related researchers and as produce, seek, use and access the scientific knowledge of your area?; and (iii) as the contexts involved in scientific collaboration processes influence in the scientific production of information science field in Brazil? The article includes a literature review on the information behavior and its insertion in scientific communication considering the influence of context and/or situation of the objects involved in motivating issues. The hypothesis is that the user information behavior in different contexts and situations influence the definition of a scientific communication model. Finally, it is concluded that the same concept or a set of concepts can be used in different perspectives, reaching up, thus, different results.
\end{abstract}

\section{Keywords}

Librarianship ; Information science ; Information behavior ; Scientific communication ; Organizational communication ; Music information ; Mediation of information 


\section{Introdução}

A necessidade de informação existe em decorrência de anseios de grupos/indivíduos em contextos e sobre temas específicos, para atender a situações determinadas. O comportamento informacional relaciona-se a essa necessidade a partir dos meios pelos quais o indivíduo busca e utiliza a informação. Desta forma, o presente artigo pretende, a partir de conceitos e modelos já consolidados na literatura, fazer uma abordagem sobre a relação entre o comportamento informacional do usuário, a comunicação científica e a mediação da informação, em contextos multidisciplinares. O artigo está estruturado em três seções, discorrendo sobre a problemática acima, porém em diferentes contextos.

O primeiro contexto versa sobre a mediação da informação realizada pelo profissional bibliotecário em ambiente educacional. Apresentam-se conceitos que identificam o profissional bibliotecário como mediador no processo de desenvolvimento do comportamento informacional do usuário, apontando competências e habilidades necessárias a uma mediação eficaz, além de um esquema representativo desse processo a partir de conceitos de mediação e de um modelo de comportamento informacional existente.

$\mathrm{Na}$ seção que trata de uma proposta de modelo de comunicação científica na área de música, esta foi desenvolvida a partir do modelo de comunicação de Tubbs e Moss (2003) correlacionando os conceitos de contextos (COURTRIGHT, 2007) e seu impacto no comportamento informacional dos pesquisadores dos subcampos acadêmico e aplicado de Música. Os dados que serviram de base para a análise e discussão do modelo neste campo foram obtidos da pesquisa de Haley et al (2010) que investigou o cenário da comunicação científica a partir das necessidades, usos e buscas de informação pelos estudiosos de universidades norteamericanas.

O compartilhamento ideológico, com condutas baseadas em normas, valores e crenças, e com relação interdependente, estrutura as atividades de pesquisa das comunidades científicas (MEADOWS, 1999; ORRICO; OLIVEIRA, 2005), e variam os intercâmbios de informação entre os seus membros (MEADOWS, 1999). A necessidade de informação dos elementos que constituem um trabalho de colaboração científica pode variar em função do contexto a qual está inserida e, consequentemente, alterar o comportamento informacional. Assim, percebe-se uma oportunidade para melhor entender quais são as forças que agem no contexto da colaboração científica que podem determinar as necessidades e comportamento por busca de informações detalhadas na última seção.

Considerando os contextos multidisciplinares, o presente artigo tem como objetivo a elaboração de modelos que exemplifiquem:

1. a atuação do bibliotecário como mediador no processo de busca e uso da informação pelo usuário, em ambiente educacional;

2. o processo de comunicação científica que contemple a variável contexto como um agente que pode influenciar no nível das atividades de pesquisa em colaboração científica de uma determinada área de conhecimento, em função das necessidades e barreiras que podem determinar o seu comportamento informacional;

3. as necessidades, busca e uso de informação na área de música, levando em conta o contexto e suas influências no comportamento informacional dos pesquisadores da área.

\section{Conceitos de comportamento informacional}

Gasquez e Costa (2010) observam que, no Brasil, a emergência de pesquisas intituladas "Comportamento Informacional de Usuários" ainda são conhecidas como "Estudos de Necessidades", contidos no tópico "Estudos de Usuários" e, apenas recentemente, o termo começa a ser empregado de forma mais intensa.

O Quadro 1 é uma revisão das autoras a respeito de como a definição de Comportamento Informacional foi sendo elaborada ao longo das pesquisas em necessidades, busca e uso das informações. 


\begin{tabular}{|c|c|}
\hline Autor & Construindo o conceito \\
\hline BRITAIN (1970) & $\begin{array}{l}\text { Estudo de usuários que comportam o uso (conhecer mecanismos de busca e uso de } \\
\text { fontes de informação), a demanda (solicitações feitas a um sistema) e necessidades } \\
\text { (confusão com demanda) de informação. }\end{array}$ \\
\hline FIGUEIREDO (1994) & $\begin{array}{l}\text { Estudo de usuários são investigações realizadas para conhecer as necessidades de } \\
\text { informação dos usuários ou para avaliar o atendimento dessas necessidades pelas } \\
\text { bibliotecas e centros de informação. }\end{array}$ \\
\hline WILSON (1999) & $\begin{array}{l}\text { Inserir o tema no campo do comportamento humano ("comportamento } \\
\text { informacional") - refere-se às atividades de busca, uso e transferência de informação } \\
\text { assumidas por um usuário que identifica suas necessidades de informação. }\end{array}$ \\
\hline WILSON (2000) & $\begin{array}{l}\text { Quatro definições relacionadas ao comportamento informacional: } \\
\text { a) comportamento informacional: totalidade do comportamento humano em relação } \\
\text { às fontes e canais de informação, incluindo informação ativa (que decorre da } \\
\text { comunicação face a face) e passiva (decorrente da ausência de interatividade entre } \\
\text { emissor e receptor); } \\
\text { b) comportamento de busca de informações: procura de informações como } \\
\text { consequência de uma necessidade para satisfazer algum objetivo; } \\
\text { c) comportamento de pesquisa de informações: vai além do mero processo de busca, } \\
\text { pesquisa com elevação do nível de refinamento, com maior envolvimento intelectual, } \\
\text { adoção de estratégias de pesquisa e julgamento de relevância dos resultados obtidos; } \\
\text { d) comportamento de uso da informação: atos físicos e mentais relacionados ao } \\
\text { envolvimento entre as informações encontradas e a base de conhecimento existente } \\
\text { da pessoa. }\end{array}$ \\
\hline $\begin{array}{l}\text { WILSON (2000); } \\
\text { PETTIGREW, FIDEL e } \\
\text { BRUCE (2001) }\end{array}$ & $\begin{array}{l}\text { Comportamento informacional são atividades que envolvem as necessidades dos } \\
\text { sujeitos e a maneira como buscam, usam e transferem a informação em diferentes } \\
\text { contextos. }\end{array}$ \\
\hline COURTRIGHT (2007) & $\begin{array}{l}\text { Fatores que influenciam a prática informacional, ou seja, o contexto é entendido } \\
\text { como "contêiner", em que os elementos existem objetivamente em torno dos atores; } \\
\text { como meio de construção de significado, em que o ponto de vista do autor é } \\
\text { valorizado na pesquisa; como construção social, em que os atores elaboram a } \\
\text { informação por meio da interação social e; como relacional, em que os conceitos de } \\
\text { ator social e contexto estão vinculados entre si. }\end{array}$ \\
\hline
\end{tabular}

Quadro 1 : Comportamento informacional nas pesquisas sobre necessidades, buscas e usos de informação pelos usuários (Fonte: Gasquez e Costa, 2010).

\section{Modelo de comunicação de Tubbs e Moss (2003)}

Para Tubbs e Moss (2003), um modelo de comunicação não é o final em si; é apenas um meio para ajudar a explicar os caminhos pelos quais as várias partes componentes do processo de comunicação interagem. 0 modelo proposto por esses autores, representado na Figura 1, é um modelo do evento de comunicação humana mais básico, que envolve duas pessoas que são representadas pelo Comunicador 1 (emissor/receptor) e pelo Comunicador 2 (receptor/emissor). Ambos são fontes de comunicação e cada um origina e recebe mensagens simultaneamente. Ambos são influenciados mutuamente na transação. O Comunicador 1 pode originar a primeira mensagem e o Comunicador 2 pode ser a primeira pessoa a perceber o estímulo transmitido, mas a maioria das atividades de comunicação diárias são espontâneas e relativamente desestruturadas, por isso são papéis que se sobrepõem. 


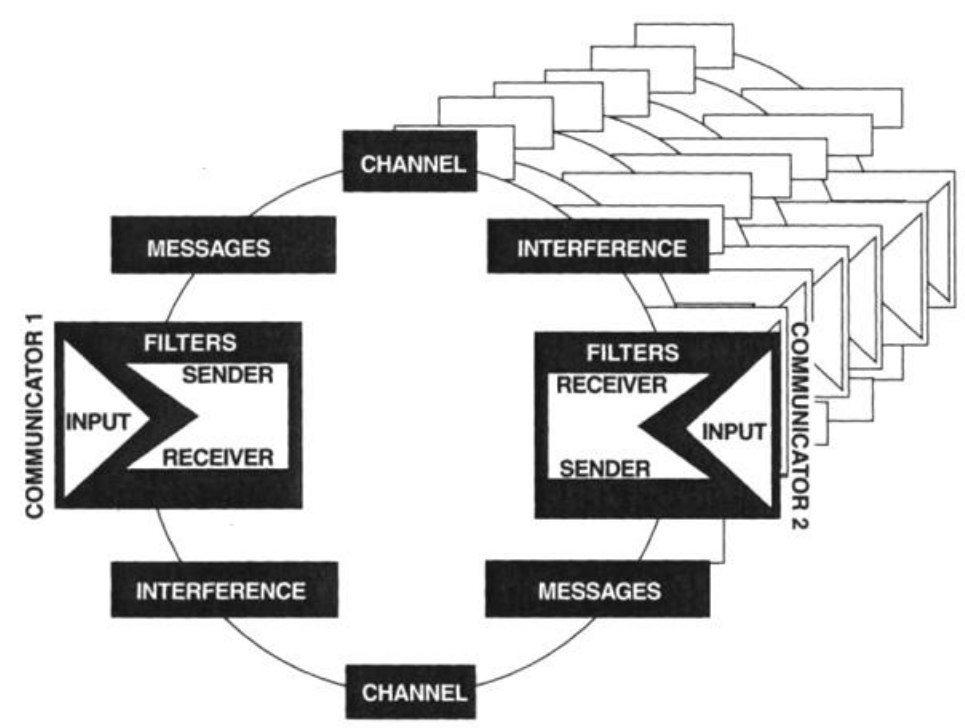

Figura 1 : Modelo de comunicação de Tubbs e Moss (Fonte: Tubbs e Moss, 2003).

Conforme o modelo apresentado, muitas transações podem ser iniciadas tanto pelo lado direito como pelo esquerdo. Isto significa uma visão transacional que enfatiza mudanças nos comunicadores/emissores/receptores como resultado de um evento. O ponto de vista transacional, então, enfatiza a natureza de influência mútua e simultânea do evento de comunicação. Os participantes se tornam independentes e sua comunicação pode ser analisada somente em termos de um contexto único do evento. Também tem sua ênfase no relacionamento entre duas ou mais pessoas envolvidas como parte de sua comunicação. As mensagens veiculadas pelo Comunicador 1 podem ser verbais ou não-verbais, e elas podem ser intencionais ou não intencionais. Então, quatro tipos de mensagens são possíveis: (i) intencional verbal; (ii) não-intencional verbal; (iii) intencional nãoverbal; e (iv) não-intencional não-verbal. À medida que examinamos essas categorias individualmente, percebese que a maioria das mensagens contém dois ou mais tipos de estímulos e que elas podem se sobrepor (TUBBS; MOSS, 2003).

Esse modelo de comunicação começa a partir de vários modelos atuais que criam a ilusão de que toda a comunicação humana tem um ponto definido de partida com um emissor e um ponto final com um receptor. Quando o comunicador recebe uma mensagem, encontra-se na metade do processo contínuo e permanente que é a comunicação. Cada receptor de uma mensagem é também um remetente da mensagem, daí, o termo "receptor /remetente." Além disso, a singularidade dessa pessoa (o emissor) como um ser humano, garante que sua ou suas tentativas para comunicar serão muito diferentes das outras no modelo. Por exemplo, o input cultural do Comunicador 2 pode ser bastante diferente do Comunicador 1. Seus filtros, tanto fisiológicos, quanto psicológicos, serão diferentes. Os estímulos que ele/ela transmite serão diferentes. Mesmo a seleção de canais e as fontes de dificuldade, ou interferência, poderão ser diferentes. O presente modelo inclui essas diferenças como partes inerentes ao processo de comunicação. Embora a parte da esquerda do modelo relaciona os mesmos elementos como o input da parte da direita, os filtros, as mensagens, os canais, a interferência e estes elementos são definidos da mesma forma, eles são sempre diferentes no conteúdo das da direita. A transmissão e a recepção de uma mensagem única são apenas parte do modelo. O face-a-face da comunicação é caracterizada pela interdependência de seus participantes e o feedback explícito e imediato entre eles. Mesmo em comunicação organizacional e de massa, onde emissor/receptor podem representar uma organização social, o receptor/remetente ainda é capaz de fornecer feedback. A interferência pode existir no contexto da comunicação, no canal, no comunicador que envia a mensagem, ou em quem a recebe. Alguma interferência estará sempre presente na comunicação humana (TUBBS; MOSS, 2003).

O tempo e sua interação entre o Comunicador 2 que responde a um Comunicador 1 pode ser representada por um círculo. Mas, à medida que a sua troca progride com o tempo, a relação entre eles é melhor descrita por vários círculos. Na verdade, todas, mas as trocas breves implicam ciclos de comunicação. Assim, o tempo se torna o elemento final do modelo de Tubbs e Moss. A presença do tempo no modelo é representada sob a forma de uma espiral, tal como uma mola desenrolada. O tempo é uma das variáveis mais relevantes no estudo da 
comunicação humana. A espiral ou o modelo transacional devem lembrar que a comunicação não é estática e que, portanto, requer diferentes métodos de análise de uma entidade fixa. O modelo identifica alguns dos principais elementos que existem em toda a comunicação que envolve seres humanos. Conforme mais comunicadores são adicionados, muda o tipo ou a quantidade de interferência, podendo variar as mensagens transmitidas, tornando o aumento dos sujeitos em complexidade. Para tentar desenvolver um modelo é necessário lembrar que há algo único cada evento de comunicação e que um modelo pode ser usado como modelo do processo de comunicação (TUBBS; MOSS, 2003).

\section{O processo de comunicação científica}

O processo de comunicação científica tem sua origem na concepção do fenômeno de pesquisa, e sua disseminação acontece desde o instante em que o pesquisador inicia os trabalhos até que os resultados sejam divulgados e incorporados à comunidade científica da área. Tal processo inclui outros elementos intermediários, conforme apresentado na Figura 2 que dispõe o modelo de comunicação científica proposto por Gavey e Griffith (1972), com adaptações de Hurd (1996) que releva também as formas eletrônicas para a disseminação do conhecimento científico.



Figura 2 - Processo de comunicação científica (Fonte: Gavey e Griffith, 1972, adaptado por Hurd, 1996).

O modelo apresenta os elementos básicos envolvidos no processo de comunicação científica, mas evidencia defasagem quando se consideram as novas formas de comunicação provenientes da evolução da tecnologia da informação, tais como blogs, micro blogs, repositórios, mecanismos de indexação e busca altamente sofisticados, entre outros.

\section{Modelo de comunicação da informação de Wilson (1999)}

Alguns dos modelos de comunicação de Wilson $(1981,1994,1997,1999)$ refletem as tendências em teoria e prática da informação para analisar e comparar com as de outros pesquisadores (como o modelo de Tubbs e Moss, por exemplo). O modelo de Wilson exposto neste artigo foi apresentado em suas pesquisas atuais bastante recentemente, no entanto, o mesmo foi baseado em diagramas, publicados originalmente em 1981. É um modelo que identifica 12 componentes, exibindo ao topo do esquema o "usuário da informação".

De acordo com Wilson (1999), o usuário da informação apresenta uma necessidade, que pode (ou não) derivar de seu nível satisfação (ou insatisfação) com informações anteriormente adquiridas. Esta necessidade percebida então leva o usuário a uma gama de atividades, momento em que externaliza seu comportamento informacional por meio da pesquisa em sistemas de informações e fontes diversas. Os resultados destas pesquisas podem levar ao sucesso (caso em que a informação é "utilizada") ou a falha, que se presume que a informação não foi encontrada ou foi insatisfatória. 
Um aspecto importante é o reconhecimento de que há a troca de informações entre indivíduos, representado no modelo como "transferência da informação", "troca de informação" e "outras pessoas" denotando outros aspectos do comportamento informacional e a existência da mediação da informação no processo.

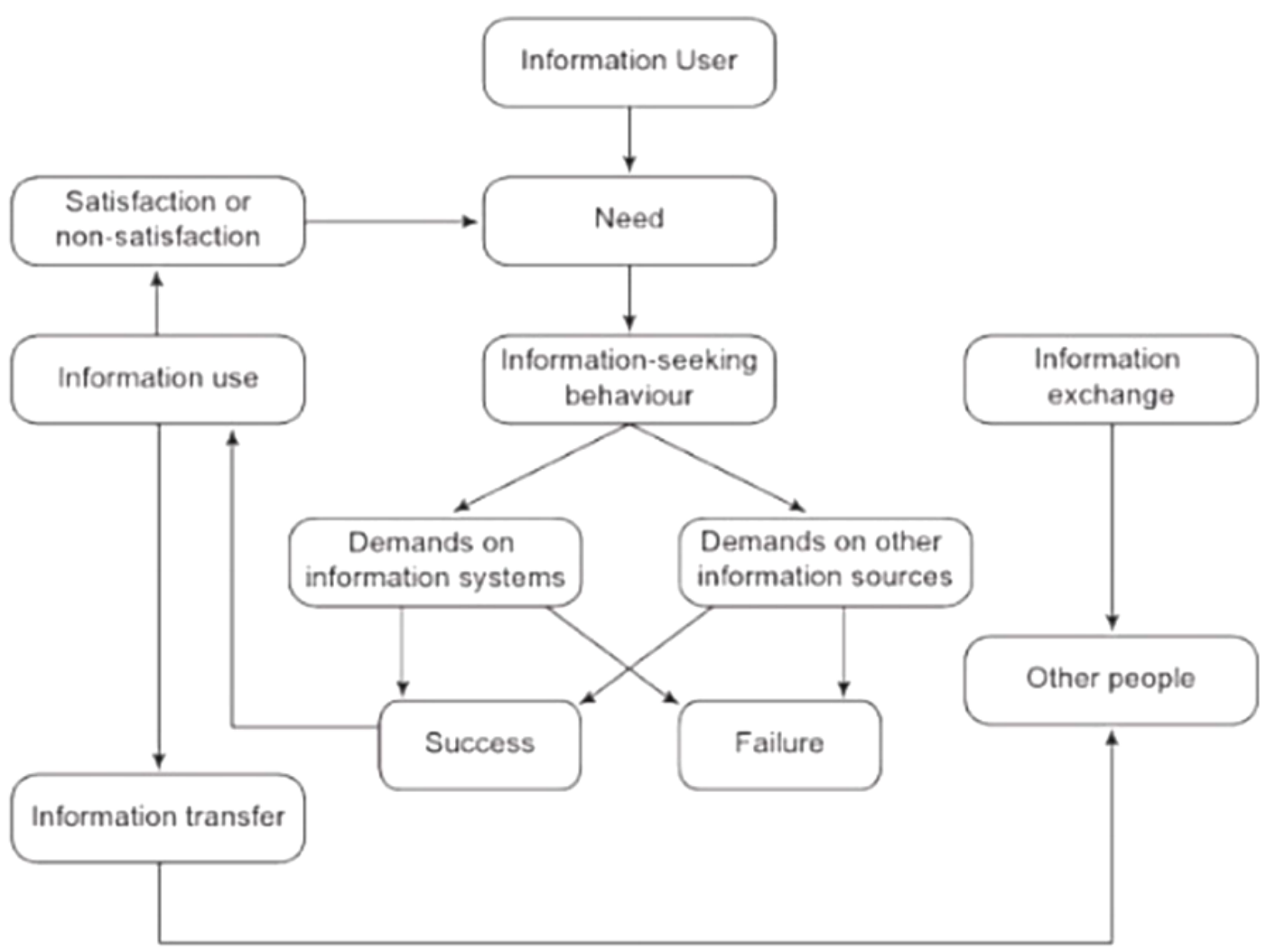

Figura 3 : Modelo de Comunicação Informacional de Thomas Wilson (Fonte: Wilson, 1999).

\section{Conceitos de mediação}

A mediação refere-se a algo mais que a comunicação humana via canais eletro/mecânicos neutros de transmissão. A mediação da comunicação humana envolve forças que influenciam o processamento de informação humana e estrutura/modela a interação social. Compreende-se mídia/meio em duas vertentes: a mecânica, que ampliam o ser físico como, por exemplo: óculos são extensões dos olhos, martelo e tesoura são extensões das mãos, carro é extensão de caminhar na concepção de Marshal Mcluhan; e a comunicativa que são extensões dos processos psicológicos. No entanto, deveria ser encontrada uma unidade para as duas para que o desenvolvimento de uma teoria da mediação seja estabelecido em uma perspectiva intelectual que facilite o estudo bem sucedido de mídia (GUMPERT; CATHCART, 1990).

Uma teoria sobre mediação, de acordo com Gumpert e Cathcart (1990), deve atentar: a) que mídia comunicativa é extensão do ser físico e psicológico; b) que a função primária e capaz de qualquer mídia é transcender tempo e/ou espaço; c) que instituições midiáticas e as propriedades intrínsecas que definem uma mídia comunicativa são separadas e distintas; d) que a gramática de cada comunicação é única; e) que dependência mídia determina expressão individual e social; f) que toda a comunicação mídia são historicamente interdependentes e; g) que toda mídia comunicativa são reflexivas e projetivas.

Para Almeida (2008, p.3), a mediação se traduz em "conexões que se estabelecem entre as ações sociais e as motivações (individuais e/ ou coletiva)" e envolve desde concepções mais antigas, como por exemplo, o atendimento ao usuário como forma de mediação, até ideias mais atuais, que incluem os agentes culturais como mediadores, ou mesmo a mediação através da elaboração de produtos que insiram o público em determinado âmbito informacional ou meio de acesso dos mesmos às tecnologias da informação e comunicação. 
De acordo com Almeida Júnior (2009, p. 92) a mediação da informação pode ser definida como "toda ação de interferência - realizada pelo profissional da informação -, direta ou indireta; consciente ou inconsciente; singular ou plural; individual ou coletiva; que propicia a apropriação de informação que satisfaça, plena ou parcialmente, uma necessidade informacional". Almeida Júnior e Bortolin (2007) afirmam ainda que a mediação da informação pode ser dividida em explícita, que está relacionada às atividades fins e implícita que se refere às atividades meio do profissional. Bicheri (2008, p. 145), afirma que:

a mediação envolve a ação de quem intercede, interfere por algo e por outro; implicando em vários caminhos, opções e escolhas. Constatamos que na mediação alguém está entre duas ou mais pessoas/coisas, facilita uma relação, serve de intermediário, sugere algo, sem agir pela pessoa ou the impor alguma coisa.

\section{Atuação do bibliotecário no processo de mediação em relação ao comportamento informacional do usuário}

A mediação do bibliotecário geralmente tem início quando o discente já sabe o que precisa e busca coletar informações. No entanto, o que se observa, nos estágios iniciais da pesquisa, onde o estudante atravessa situações de ansiedade e dúvida, é que não ocorre a atuação efetiva do bibliotecário para auxiliá-lo. O bibliotecário deveria atuar desde o primeiro momento da necessidade de informação, juntamente com os docentes da instituição, assumindo também, dessa maneira, o papel de educador (DUDZIAK, GABRIEL E VILLELLA, 2000).

Kuhlthau (1993), define alguns níveis de mediação que podem ser assumidos pelo bibliotecário como mediador em um procedimento de pesquisa: a) organizador: atua em nível operacional; b) localizador: responde a questionamentos e localiza a informação solicitada; c) identificador: realiza entrevista com o usuário, para a identificação do problema de pesquisa e indica as melhores fontes de informação; d) conselheiro: realiza entrevista com o usuário, para melhor entendimento do problema de pesquisa, negocia e recomenda fontes de informação e; e) tutor: intervém no processo, realiza buscas estruturadas, interage com o estudante sugerindo estratégias, faz recomendações, redefine procedimentos de pesquisa, atua conjuntamente com o usuário no processo de investigação científica.

\section{Competências necessárias ao bibliotecário que atua como mediador no contexto educacional}

No processo de mediação, o bibliotecário deve assumir o papel de educador. Dudziak, Gabriel e Villela (2000), relacionam algumas competências necessárias ao bibliotecário que atua como mediador em âmbito educacional:

aptidão para expressar-se e comunicar-se, criando um ambiente que estimule o aprendizado, utilizando técnicas de transmissão de informações efetivas;

2. deve ostentar o papel de tutor, possuindo a capacidade de interagir com seus usuários e auxiliá-los em todas as etapas do processo de busca da informação;

3. familiaridade com os recursos informacionais disponíveis e os instrumentos de busca e acesso às informações, tanto no formato eletrônico quanto no tradicional, nas mais variadas áreas do conhecimento.

No desenvolvimento de suas competências profissionais Dudziak, Gabriel e Vilela (2000) também enfatizam o aprimoramento das seguintes habilidades: atuação direta com o cliente/usuário e comunidade na qual esteja inserido; sólidos conhecimentos das fontes de informação; capacidade de avaliar a qualidade da informação; desenvolvimento de pensamento estratégico; atitude voltada ao aprendizado permanente; compartilhamento e intercâmbio de conhecimentos; visão sistêmica da realidade; ampliação da capacidade organizacional; capacidade de seleção; capacidade de tomada de decisão e; desenvolvimento de parcerias. 


\section{Modelo de mediação da informação realizada pelo bibliotecário em contexto educacional}

O esquema apresentado na Figura 4 foi elaborado a partir do modelo de comportamento informacional proposto por Wilson (1999, p. 3) e adaptado ao contexto do comportamento informacional em ambiente educacional, tendo o bibliotecário como mediador entre o usuário e o acesso à informação. $O$ modelo apresenta as relações existentes entre as etapas que compõem o procedimento de busca da informação, os resultados possíveis e a presença do bibliotecário como mediador do processo.

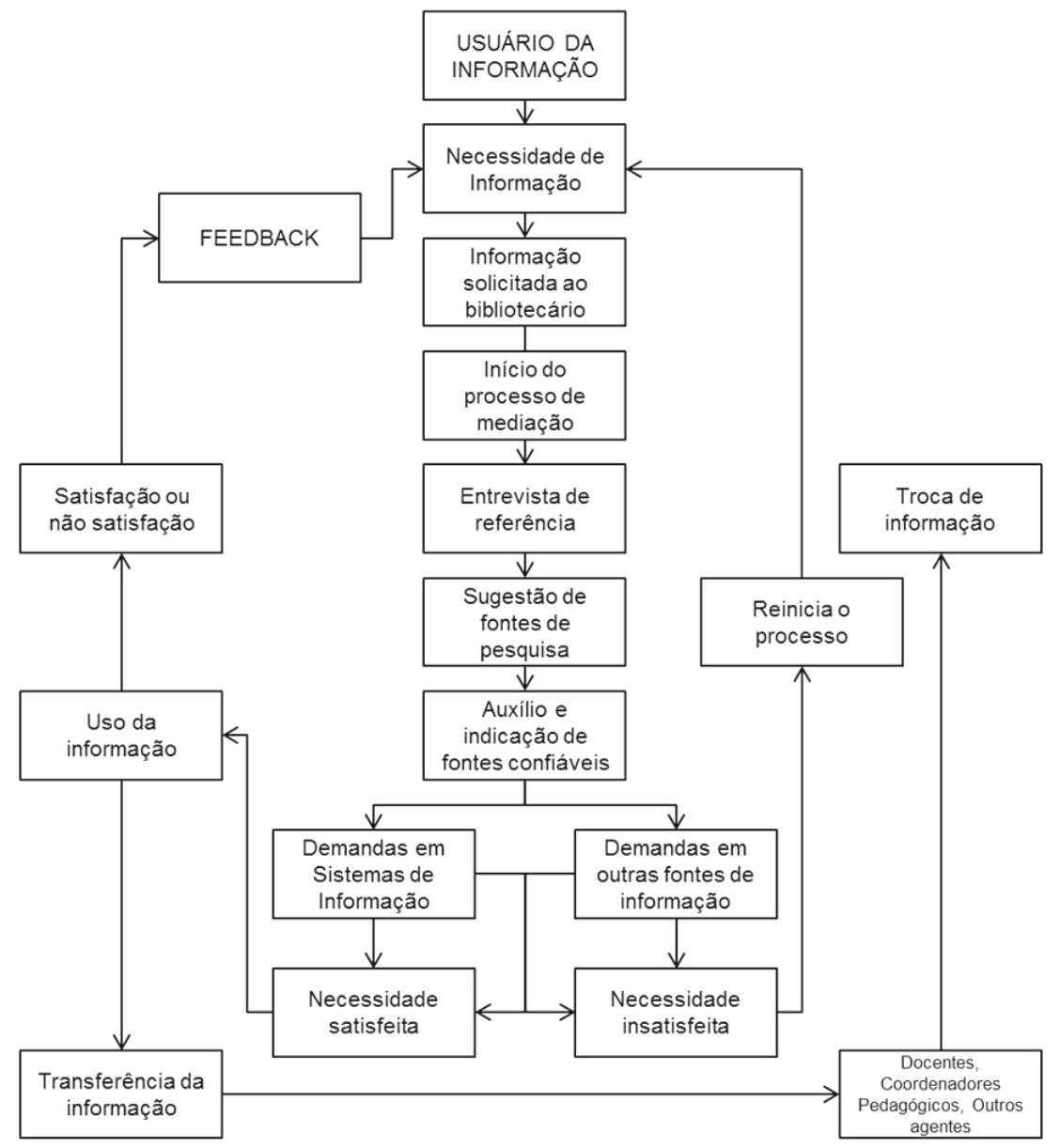

Figura 4 - Modelo de comportamento Informacional em ambiente educacional. Adaptação do modelo de Wilson (1999, p. 3).

Foram acrescentados ao modelo alguns componentes, além dos doze existentes, como por exemplo a entrevista de referência, que é o momento em que se questiona o usuário, para compreender sua necessidade de pesquisa; a importância do "feedback", para que o bibliotecário tenha condições de avaliar se suas competências como mediador estão realmente adequadas às necessidades do público alvo e também a questão da "conveniência de reavaliação e/ou reinício" dos procedimentos adotados em caso de falha no processo.

\section{Um modelo de comunicação baseado nas necessidades, busca e uso de informações pelos pesquisadores da área de música}

A proposta de um modelo que contempla a relação das necessidades, busca e uso de informação e comportamento informacional entre os pesquisadores da área de Música foi construída a partir de uma pesquisa realizada pelo Center for Studies in Higher Education (CSHE) da Universidade da Califórnia. Esse Centro desenvolveu um estudo exploratório a respeito do futuro da Comunicação Científica em sete áreas do conhecimento: Arqueologia, Astrofísica, Biologia, Economia, História, Música e Ciências Políticas. O estudo teve a seguinte problemática: como a universidade e seus diversos públicos, formado principalmente por docentes, 
enfrentam os valores tradicionais e as formas emergentes que envolvem a Comunicação Científica. A investigação procurou compreender quais as necessidades do corpo docente e suas práticas para o progresso da comunicação e publicação científicas. Os objetivos desse projeto foram mapear e avaliar sistematicamente, no nosso caso, na área de Música: a) as necessidades atuais e sua evolução na comunicação científica dos pesquisadores, ou seja, avaliar suas atitudes de necessidades como produtores e utilizadores dos resultados das pesquisas; b) a capacidade de vários modelos tradicionais e emergentes de comunicação e publicação para a atender a essas necessidades; c) os prováveis cenários futuros para a comunicação científica, e como esses cenários podem ser melhor apoiados pelas organizações institucionais e unidades (por exemplo, os departamentos, bibliotecas, editoras comerciais, sociedades, etc.) (HALEY et al, 2010).

A metodologia, primeiramente, utilizou-se de entrevistas com professores, complementada por entrevistas com os responsáveis pela implementação de iniciativas inovadoras da publicação acadêmica incluindo bibliotecários, editores e profissionais de TI. Estas entrevistas formaram a base principal para os estudos de casos disciplinares. Algumas das entrevistas foram gravadas em áudio, e cada entrevista gravada foi transcrita, resumida e analisada. Os dados foram organizados nos seguintes tópicos que foram divididos em dois subcampos dentro da área de Música, o acadêmico e o aplicado:

1. requisitos para posse e promoção: quais as qualificações para o sucesso acadêmico;

2. desafios e oportunidades para a disseminação da pesquisa: quais os critérios para a escolha de uma mídia;

3. como os pesquisadores da área compartilham seus trabalhos com seus pares;

4. como os pesquisadores colaboram entre si e em que estágio da pesquisa;

5. quais as necessidades para a condução da pesquisa, como os pesquisadores realizam suas pesquisas, o que precisam mudar no processo e se sabem do que necessitam;

6. em que nível, como e por que os pesquisadores e seus pares se envolvem com o público.

$\mathrm{Na}$ Figura 5, apresenta-se uma resumida visão dos principais subcampos da área de Música com as necessidades, busca e uso de informações de seus pesquisadores.

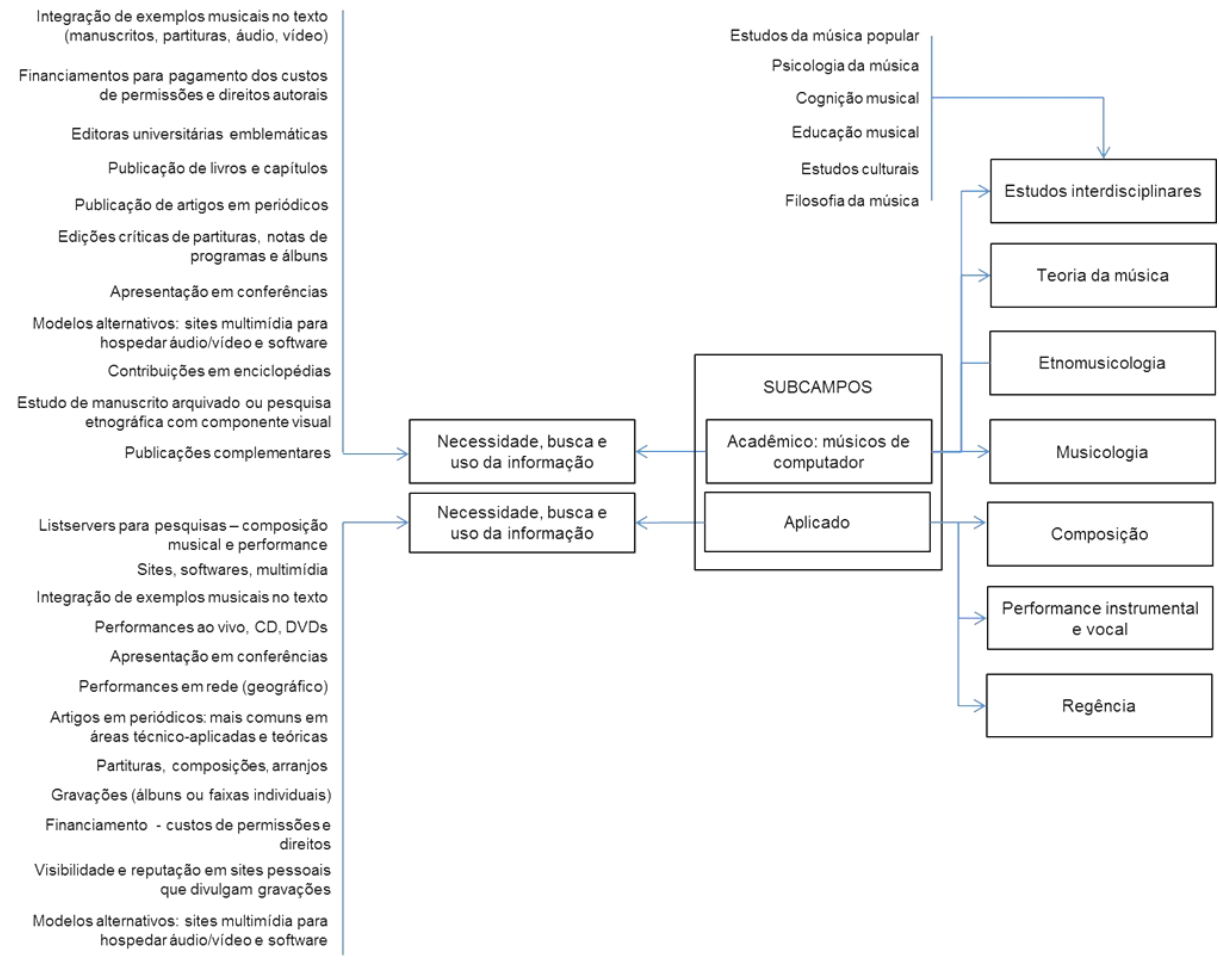

Figura 5 - Visão geral da área de Música (Fonte: Haley et al, 2010). 
Consoante aos conceitos apresentados anteriormente sobre mediação, comportamento informacional e nos modelos de comunicação de Tubbs e Moss (2003), das definições de contextos (COURTRIGHT, 2007) e dos conceitos de comportamento informacionais e das práticas informacionais de busca, de uso e de pesquisa (WILSON, 2000), elaborou-se, de acordo com a Figura 6, o modelo de comunicação científica baseado nas necessidades, busca e uso de informações pelos pesquisadores na área de Música com base nos resultados das pesquisas do CSHE (HALEY, 2010).

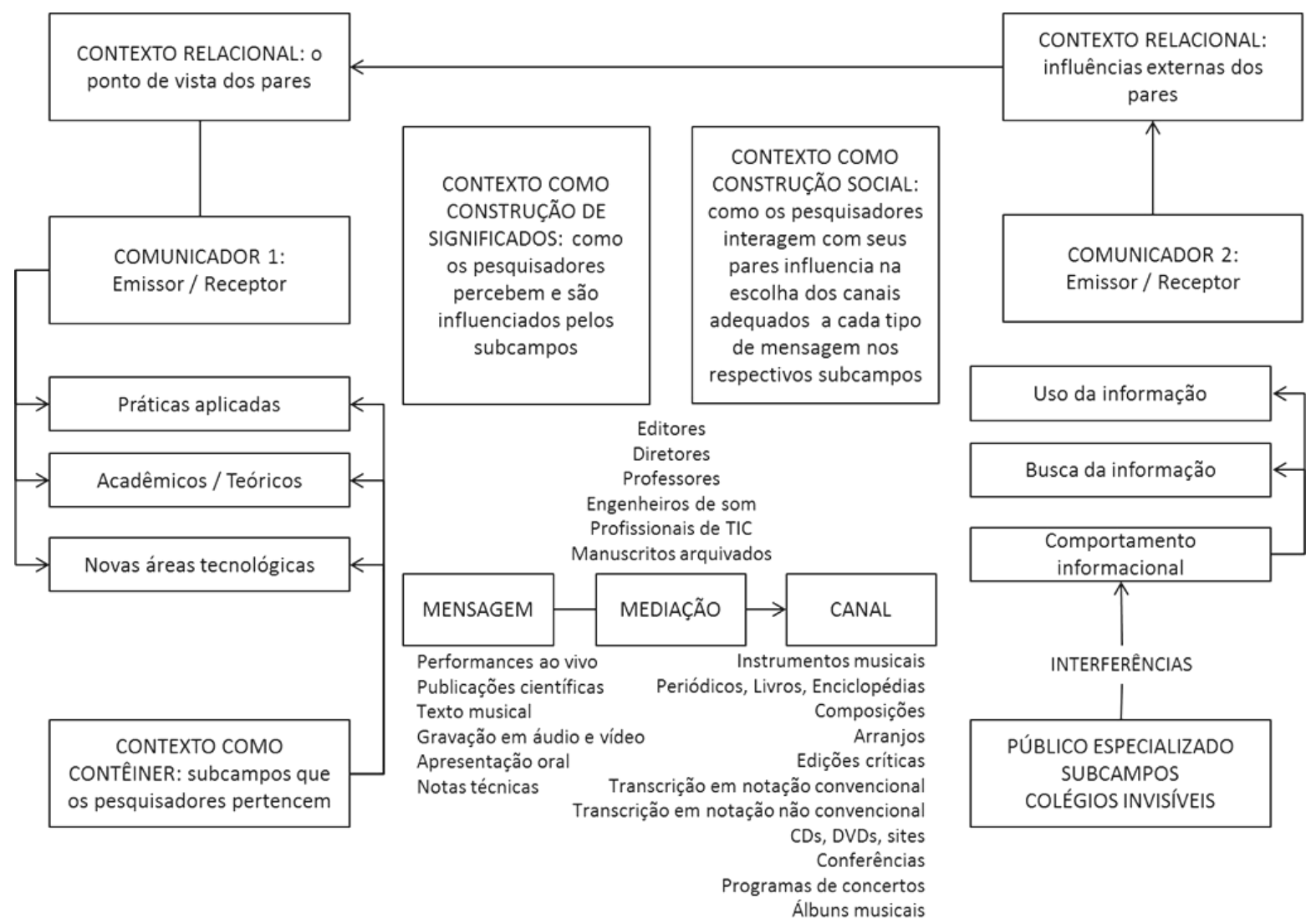

Figura 6 - Modelo de comunicação baseado nas necessidades, busca e uso de informações pelos pesquisadores da área de música

\section{Um modelo de processo de comunicação científica: colaboração científica}

A colaboração científica pressupõe um trabalho conjunto de pesquisadores para alcançarem o objetivo comum de produzir novo conhecimento científico (KATZ; MARTIN, 1997, p.13), viabilizado pelo compartilhamento de ideais centrais, clima de confiança, divisão de trabalho, interação entre as diferentes relações do investimento conjunto (OLIVEIRA; GRÁCIO, 2008, p.38).

A cooperação direta entre dois ou mais pesquisadores pode ser considerada como o principal elemento da colaboração, que tem outros níveis: (i) entre grupos de pesquisa; (ii) entre departamentos de uma instituição; (iii) entre instituições; (iv) entre setores; e (v) entre regiões geográfica e países (KATZ; MARTIN, 1997, p.10).

A pesquisa científica realizada em colaboração tem sido incentivada por governos, agências de fomento, instituições de pesquisa e universidades, e prestigiada por editores, avaliadores e grupos científicos (VILAN FILHO et alii, 2008, p.4), e oferece uma fonte de apoio para melhorar o resultado e maximizar o potencial da produção científica (BALANCIERI et alii, 2005, p.2). 


\section{Produção científica}

Meadows (1999) relaciona produção científica à qualidade e a quantidade do que é produzido. Para concretizar a reflexão sobre a literatura de um campo do conhecimento faz-se necessário pensar nas diversas possibilidades e suportes dessa produção científica, quando se evidencia a evolução de saberes e práticas relacionadas, destacando-se novos conceitos e suas respectivas definições, concretizados em domínio científico específico (BUFREM et alii, 2007, p. 48).

Cabe ressaltar que a produção científica não se restringe aos periódicos compartilhados, mas abarca todas as realizações inerentes à pesquisa, ensino e aplicação prática da ciência, de onde podem resultar serviços, métodos e tecnologias em uma atividade de extensão à sociedade (MUGNAINI et alii, 2006). Contudo, a produção científica divulgada em periódicos científicos é importante para a constituição da ciência no âmbito acadêmico ao tornar o artigo um poderoso veículo de disseminação da informação científica (SILVEIRA, 2012, p.119).

Embora a divulgação científica em livros seja o principal canal de comunicação da área de Ciências Sociais Aplicadas (MUELLER, 2005), o advento dos periódicos eletrônicos também tem contribuído para a mudança do cenário de produção, disseminação e uso da informação científica, tudo fomentado pelas novas tecnologias da informação que permeiam os processos da comunicação científica.

\section{Indutores da colaboração científica: colaboração científica para a produção científica}

O desenvolvimento colaborativo entre pesquisadores individuais pode resultar, por exemplo, em amplos centros de excelência, ou em grupos de pesquisa interdisciplinares. Enquanto existem fatores que aparentemente contribuem para a atividade colaborativa, enquanto um processo intrinsecamente social (níveis de financiamento, aumento de visibilidade e reconhecimento científico, aumento da especialização e profissionalismo em ciência, necessidade de aquisição de experiência, entre outros), há poucas razões específicas estabelecidas para explicar o porquê esse fenômeno ocorre (KATZ; MARTIN, 1997, p.7).

Katz e Martin (1997) identificam alguns fatores que podem ser responsáveis pelo avanço da colaboração científica: (i) financiamento; (ii) capital científico (visibilidade e reconhecimento); (iii) incremento da especialização na ciência; (iv) avanço das disciplinas científicas que requerem mais conhecimentos; (v) custo; (vi) tempo, entre outros. Meadows (1999) também considera que a especialização da atividade de pesquisa potencializa a colaboração científica.

O modelo de Wilson, que ressalta a questão da influência dos papeis desempenhados pelo indivíduo no seu comportamento informacional, inclui as barreiras do ambiente pessoal, interpessoal e o contexto social no processo de busca da informação (FAUAT, 2007), conforme apresentado na Figura 7.

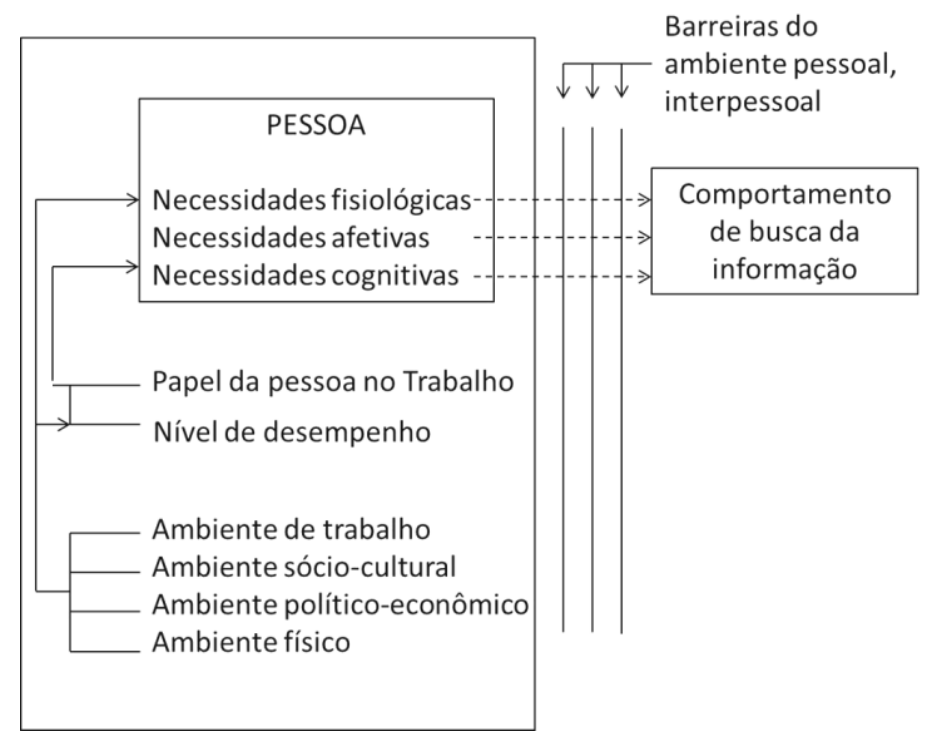

Figura 7 - Modelo de comportamento informacional (adaptado de Fauat, 2007). 
Seguindo o modelo de comportamento informacional de Wilson (1999), e considerando os elementos previstos no processo de comunicação modelado por Gavey e Griffith (1972), adaptado por Hurd (1996), percebe-se que o comportamento informacional da comunidade científica de uma determinada área pode variar em função do contexto a qual está inserida. Além disso, a necessidade de informação, que é externada pelos próprios membros da comunidade científica, pode interferir no comportamento informacional, quando comparado à análise de FAUAT (2007).

A ideia deste item é propor a adaptação de um modelo de processo de comunicação científica que considere que a variável "contexto" pode influenciar efetivamente no nível atividades de pesquisa de uma determinada comunidade científica, em função das necessidades (fisiológicas, afetivas, cognitivas, tecnológicas, informação) e das barreiras (pessoais, interpessoais, tecnológicas, financeiras) que podem determinar o seu comportamento informacional (Figura 8).

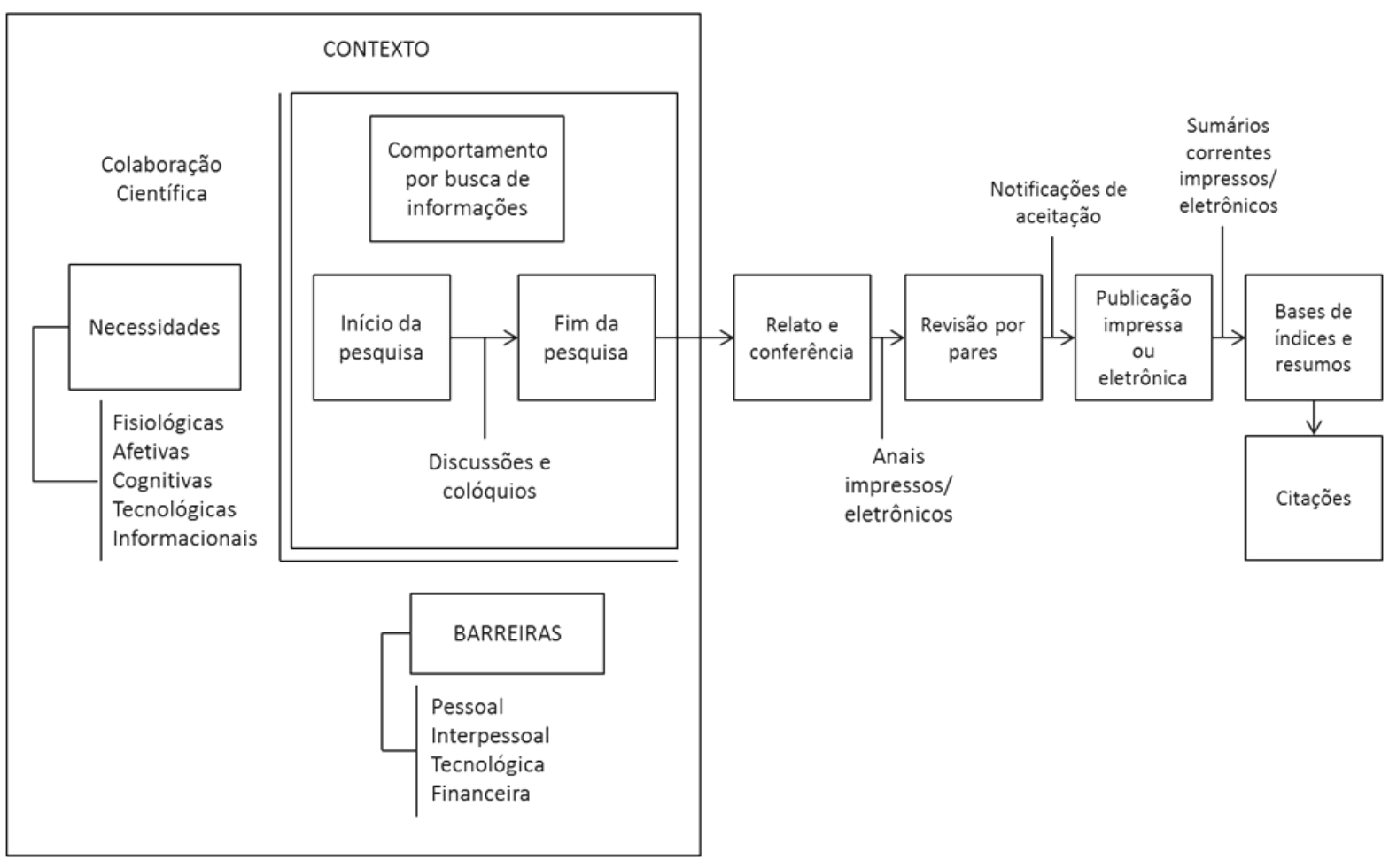

Figura 8 - Proposta de adaptação do modelo de processo de comunicação científica.

Sob a perspectiva da comunicação científica, alinhando os conceitos envolvidos nos modelos de Wilson e de Gavey e Griffith, percebe-se que o comportamento informacional pode constituir o comportamento dos membros da comunidade científica no que tange às fontes e canais de informação. Os procedimentos de recuperação da informação podem ser resultados da própria necessidade de informação para que os resultados da pesquisa sejam alcançados. As atividades de busca, tratamento e uso da informação podem envolver inferências particulares dos pesquisadores, características físicas e mentais, além do ambiente e do contexto. Esse cenário pode ser determinante para a manutenção da produção científica de uma determinada área de conhecimento.

\section{Conclusões}

Ao adaptar um modelo de comportamento informacional existente ao contexto educacional, observa-se que o bibliotecário atua como mediador em todos os momentos explicitados no esquema. No entanto, o modelo adotado na Figura 2 permite que a mediação da informação pelo bibliotecário seja visualizada apenas a partir do momento em que o usuário necessita de uma informação (mediação explícita), quando na realidade a mediação ocorre antes mesmo de uma necessidade iminente (mediação implícita). 
O bibliotecário que atua em âmbito educacional opera como mediador desde o momento em que prepara a unidade de informação para atender à demanda, adequando o acervo aos projetos pedagógicos, adotando políticas de seleção, organizando a informação para sua posterior disponibilização, preparando projetos de incentivo à leitura, à pesquisa e capacitação de usuários, interagindo com os demais agentes educacionais, dentre inúmeras outras atividades que realizam, para que a informação seja a mais satisfatória possível a quem dela necessite.

Na elaboração do modelo de comunicação científica na área de Música, dois problemas foram detectados, um diz respeito à limitação dos tipos de mensagem de Tubbs e Moss (2003) e outro, à complementariedade das diferentes definições de contextos trazidos na revisão de Courtright (2007). No primeiro, entendeu-se que a área de Música comunica mensagens, produtos de suas pesquisas científicas nos diferentes subcampos e levando em conta a interdisciplinaridade, incomuns da maioria dos outros campos do conhecimento. Na música, a performance de uma obra inédita ou não é resultante de uma pesquisa, seja da exploração de novos elementos sonoros para a composição ou do estudo das técnicas composicionais e de interpretação de um período histórico específico. No caso da Etnomusicologia, percebe-se o desenvolvimento de novas grafias musicais ou de novas técnicas de gravações das manifestações musicais presentes em uma determinada cultura.

Ao propor o modelo, também foram utilizados os diferentes significados de contexto no percurso do processo comunicativo. Sabendo que, o contexto relacional permeia todo o esquema, em alguns momentos considera-se a influência dos outros em determinados momentos e que modificam a maneira como os pesquisadores da área enxergam suas necessidades, buscam e utilizam as informações nos respectivos subcampos da Música. No caso do estudo em particular que foi a base para as reflexões do modelo, as necessidades, a procura e o uso das informações nos seus subcampos estão relacionadas à posse e promoção na carreira dentro das universidades norte-americanas (critérios um pouco diferentes da realidade das universidades brasileiras); ao tipo do formato para a comunicação da pesquisa (aqui se inserem arquivos de áudio, vídeo, performances ao vivo, softwares, texto musical, permissões de uso/ direitos autorais de exemplos musicais e outros); à colaboração com os pares; à condução da pesquisa e ao envolvimento com o público especializado e geral.

Ao final do presente trabalho conclui-se que um mesmo conceito, ou um conjunto de conceitos pode ser utilizado em diferentes perspectivas e obtendo-se também diferentes resultados. Os conceitos de comunicação, comportamento informacional e mediação perpassaram por todos os tópicos de pesquisa, sendo que em cada um deles assumiram uma abordagem diferenciada, mas sem perderem sua caracterização.

\section{Referências}

ALMEIDA, M. A. de. Mediações da cultura e da informação: perspectivas sociais, políticas e epistemológicas. Tendências da Pesquisa Brasileira em Ciência da Informação, América do Norte, v.126, n.9, 2008.

ALMEIDA JÚNIOR, O. F. de. Mediação da informação e múltiplas linguagens. Pes. bras. Ci. Inf. Brasília, v.2, n.1, p.89-103, jan./dez. 2009.

ALMEIDA JÚNIOR, O. F. de; BORTOLIN, S. Mediação da Informação e da Leitura, 2007. In: Seminário em Ciência da Informação, 2., 2007, Londrina. Anais...Londrina: UEL, 2007.

BALANCIERI, R. et al. A análise de redes de colaboração científica sob as novas tecnologias da informação e comunicação: um estudo na Plataforma Lattes. Ciência da Informação, Brasília, v.34, n.1, p.64-77, 2005.

BICHERI, A. L. A. de O. A mediação do bibliotecário na pesquisa escolar face a crescente virtualização da informação. 2008. 197 f. Dissertação (Mestrado em Ciência da Informação)- Faculdade de Filosofia e Ciências, Universidade Estadual Paulista, Marilia, 2008.

BUFREM, L. S. et al. Produção científica em Ciência da Informação: análise temática em artigos de revistas brasileiras. Perspectivas em Ciência da Informação, v.12, n.1, p.38-49, jan-abr 2007.

COURTRIGHT, C. Context in Information Behavior Research. Annual Review of Information Science and Technology, v. 41, p. 273-306, 2007.

FAUAT, A. M. Comunicação organizacional e padrões de comportamento informacional de gestores e analistas de risco de crédito em instituições financeiras governamentais. 154 f. Dissertação (Mestrado)- Faculdade de Ciência da Informação, Universidade de Brasília, 2007.

GASQUE, K. C. G. D; COSTA, S. M. S. Evolução teórico-metodológica dos estudos de comportamento informacional de usuários. Ciência da Informação, Brasília, DF, v. 39 n. 1, p.21-32, jan./abr., 2010. 
HURD, J. et alli. The changing scientific and technical communication system. In: From print to electronic. ASIS, 1996.

KATZ, J. S.; MARTIN, B. R. What is research collaboration. Research Policy, v. 26, p.1-18, 1997.

KUHLTHAU, C.C. Seeking meaning. Norwood: Ablex, 1993.

MEADOWS, Arthur Jack. A comunicação científica. Brasília: Briquet de Lemos/Livros, 1999.

MUELLER, S. P. M. Publicação da ciência: áreas científicas e seus canais preferenciais. DataGramaZero, v.6, n.1, 2005.

MUGNAINI, R. et alii. Indicadores bibliométricos da produção científica brasileira: uma análise a partir da base Pascal. Ci. Inf., Brasília, v.33, n.2, p.123-131, maio/ago. 2004.

ORRICO, E. G. D.; OLIVEIRA, C. I. C. de. A representação metafórica nos caminhos do conhecimento em tempos de comunicação globalizada. DataGramaZero, v.6, n.5, out 2005.

PETTYGREW, K. E.; FIDEL, R.; BRUCE, H. Conceptual frameworks in information behavior. ARIST, Meldford, v. 35, 2001. p. 43-78.

SILVEIRA, J. P. B. A produção científica em periódicos institucionais: um estudo da revista Biblios. Encontros Bibli: revista eletrônica de biblioteconomia e ciência da informação, v.17, n.33, p.116-133, jan-abr, 2012.

TUBBS, S. L.; MOSS, S. Human communication: principles and contexts. 9. ed. Boston: McGraw-Hill, 2003.

VILAN FILHO, J. L. et al. Artigos de periódicos científicos das áreas de informação no Brasil: evolução da produção e da autoria múltipla. Perspectivas em Ciência da Informação, v. 13, n. 2, p.2-17, maio/ago 2008.

VILAN FILHO, J. L.; MUELLER, S. P. M. A colaboração nos artigos brasileiros de informação: o peso das parcerias orientadororientando. Encontro Brasileiro de Bibliometria e Cientometria. 2., São Carlos, 2010.

VILAN FILHO, J. L. Autoria Múltipla em Artigos de Periódicos Científicos das Áreas de Informação no Brasil. 2010.215 f. Tese (Doutorado) - Curso de Ciência da Informação, Departamento de Faculdade de Ciência da Informação, Universidade de Brasília, Brasília, 2010

WILSON, T, D. Human information behavior. Informing Science, Califórnia, v. 3, n. 2, p. 49-56, 2000.

Models in information behaviour research. Journal of Documentation, Sheffield, v.55, n. 3, p. 249-270, 1999. 


\section{Dados dos autores}

Cecília Morena Maria da Silva

Bibliotecária na Procuradoria-Geral do Distrito Federal. Bacharel em Biblioteconomia (2006) e Especialista em Gestão Pública (2008) pela Universidade Federal de Goiás (UFG). Mestranda em Ciência da Informação na Universidade de Brasília (UnB).

cecilia.morenna@gmail.com

\section{Jonathan Rosa Moreira}

Adjunto de desenvolvimento de sistemas da Divisão de Simulação de Combate do Comando de Operações Terrestres do Exército Brasileiro. Bacharel em Sistemas de Informação pela Faculdade Cenecista de Brasília Campanha Nacional de Escolas da Comunidade (2008), MBA em Governança em Tecnologia da Informação pelo Centro Universitário do Maranhão (2009), Especialista em Educação e Tecnologias para Educação a Distância pela Universidade Cidade de São Paulo (2011) e em Gestão de Processos Acadêmicos pela Faculdade Projeção (2013), Mestre em Gestão do Conhecimento e Tecnologia da Informação pela Universidade Católica de Brasília (2011), Doutorando em Ciência da Informação na Universidade de Brasília.

jonathanmoreira@gmail.com

\section{Juliana Rocha de Faria Silva}

Professora de ensino básico, técnico e tecnológico do Instituto Federal de Educação, Ciência e Tecnologia de Brasília (IFB). Graduação em Educação Artística Habilitação - Licenciatura em Música pela Universidade Federal de Uberlândia (2001). Mestre em Educação Musical pela Universidade de Brasília (2010). Doutoranda em Ciência da Informação na Universidade de Brasília (UnB).

jurfsilva@gmail.com

Recebido-Received : 2014-09-25

Aceitado-Accepted : 2014-12-30

\section{(cc) $\mathrm{BY}$}

This work is licensed under a Creative Commons Attribution 4.0

United States License.

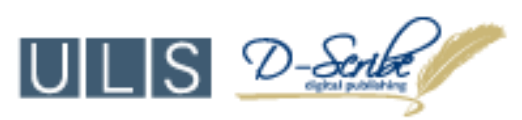

This journal is published by the University Library System of the University of Pittsburgh as part of its D-Scribe Digital Publishing Program and is cosponsored by the University of Pittsburgh Press. 